Supporting Information

\title{
Blending characteristics of isooctene, MTBE and TAME as gasoline components
}

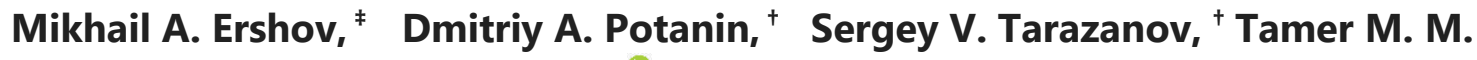 \\ Abdellatief ${ }^{*},{ }^{*} \S \odot$ and Vladimir M. Kapustin ${ }^{*}$ \\ ‡) Technology of oil refining department, faculty of chemical and environmental engineering, \\ Gubkin Russian State University of Oil and Gas (National Research University), Moscow, \\ 119296, Russia. \\ †) Automotive and aviation gasoline department, «All-Russia Research Institute of Oil Refining» \\ Joint Stock Company (VNII NP JSC), Moscow, 111116, Russia. \\ ${ }^{\S)}$ Chemical engineering department, faculty of engineering, Minia University, EL-Minia, 61519, \\ Egypt.
}




\section{Supplement materials}

Fig. S1. Induction period of isooctene and isooctane blends.

Fig. S2. ASTM Distillation Curve for isooctene Sample.

Fig. S3. Effect of isooctene on the change in the RVP of the base gasoline A and B in comparison with MTBE and TAME.

Fig. S4. Effect of isooctene on the change in the MON of the blend "70".

Fig. S5. Effect of isooctene on the change in RON of base gasoline A and B in comparison with MTBE and TAME.

Fig. S6. Influence of isooctene on the change of motor octane number of base automobile gasoline (A and B), MTBE, and TAME.

Table S1. Physico-chemical and operational characteristics of the isooctene sample.

Table S2. Effect of isooctene on the change in octane numbers of base components and reference blend "70". 


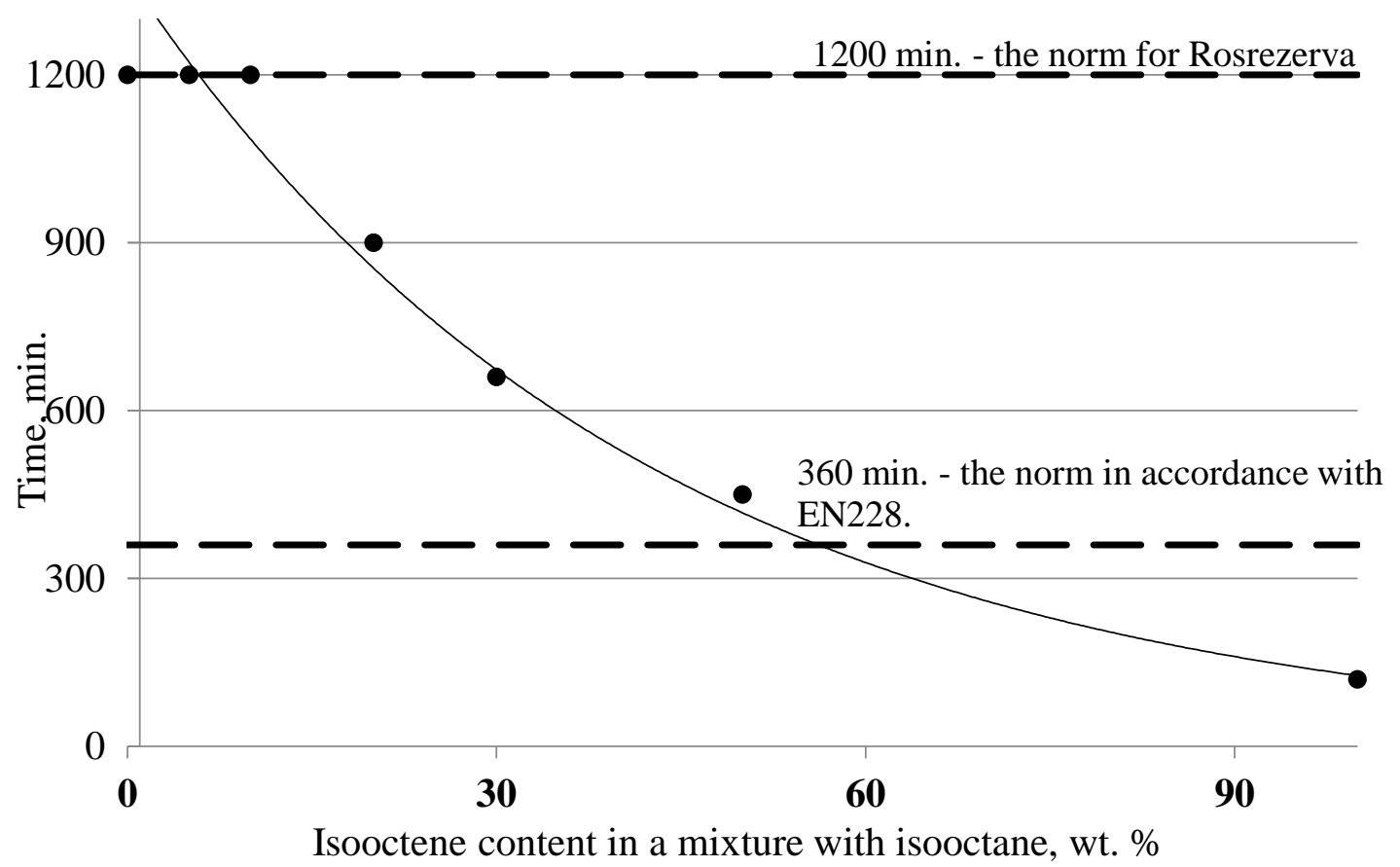

Fig. S1. Induction period of isooctene and isooctane blends. 


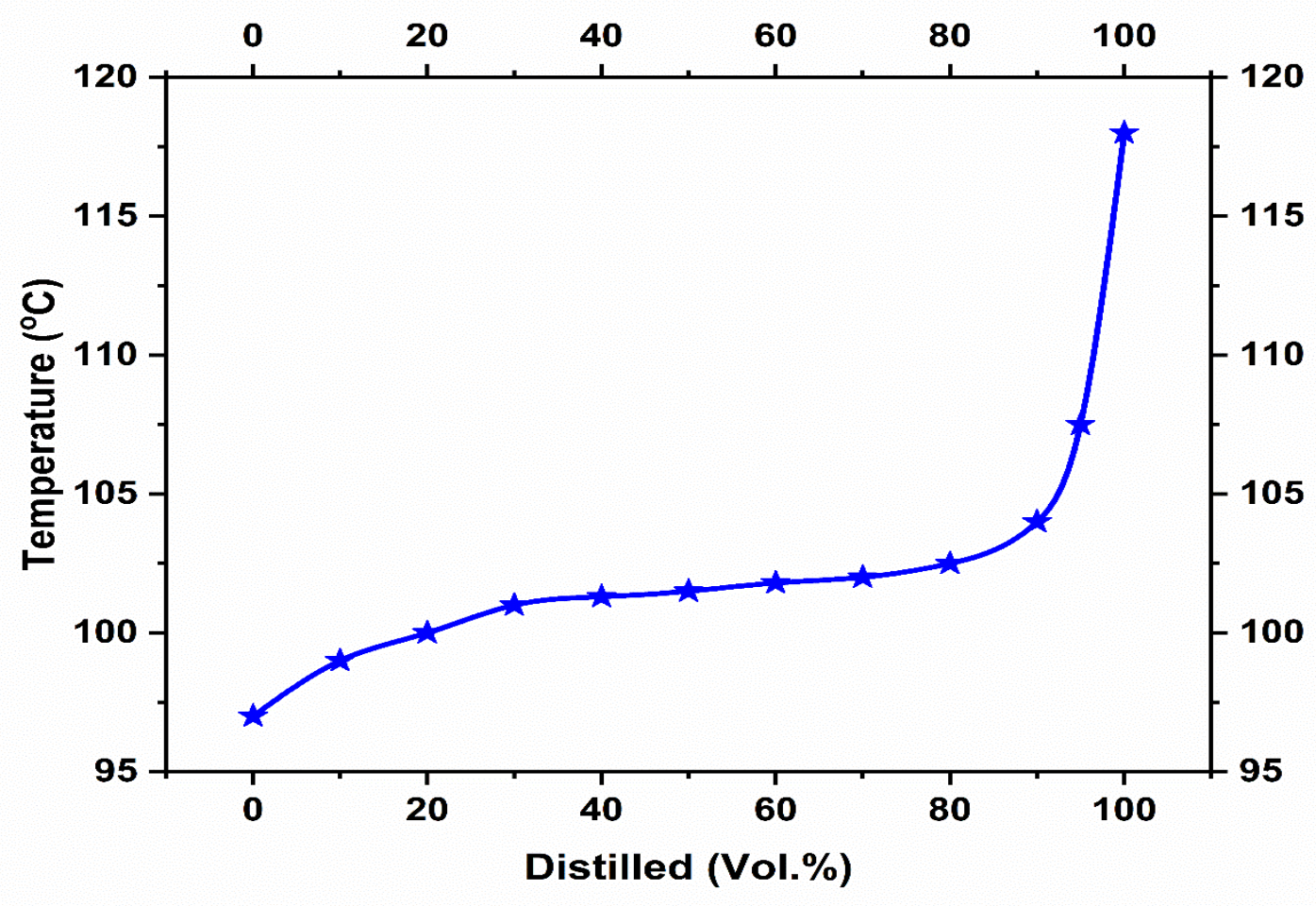

Fig. S2. ASTM Distillation Curve for isooctene Sample. 

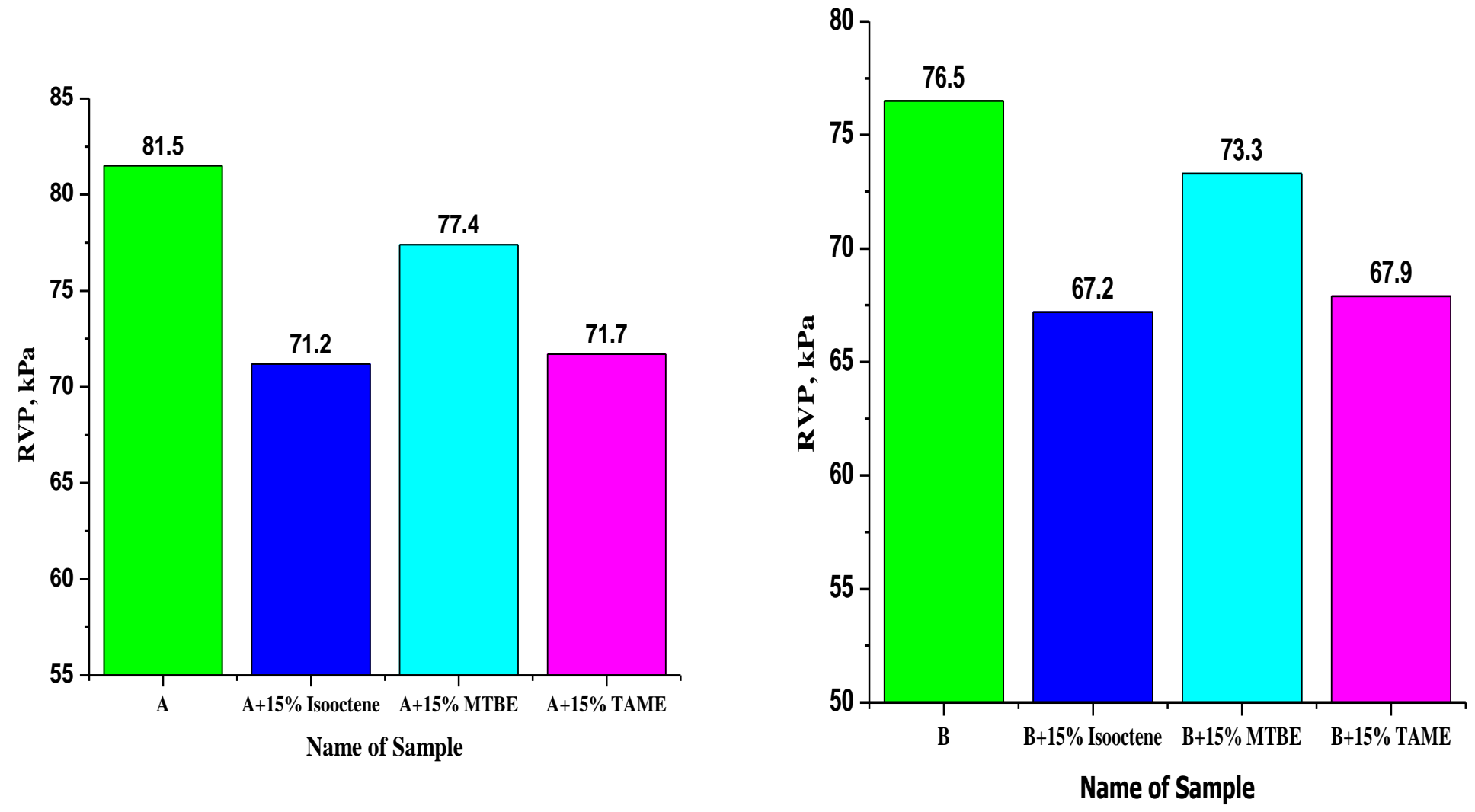

Fig. S3. Effect of isooctene on the change in the RVP of the base gasoline A and B in comparison with MTBE and TAME. 


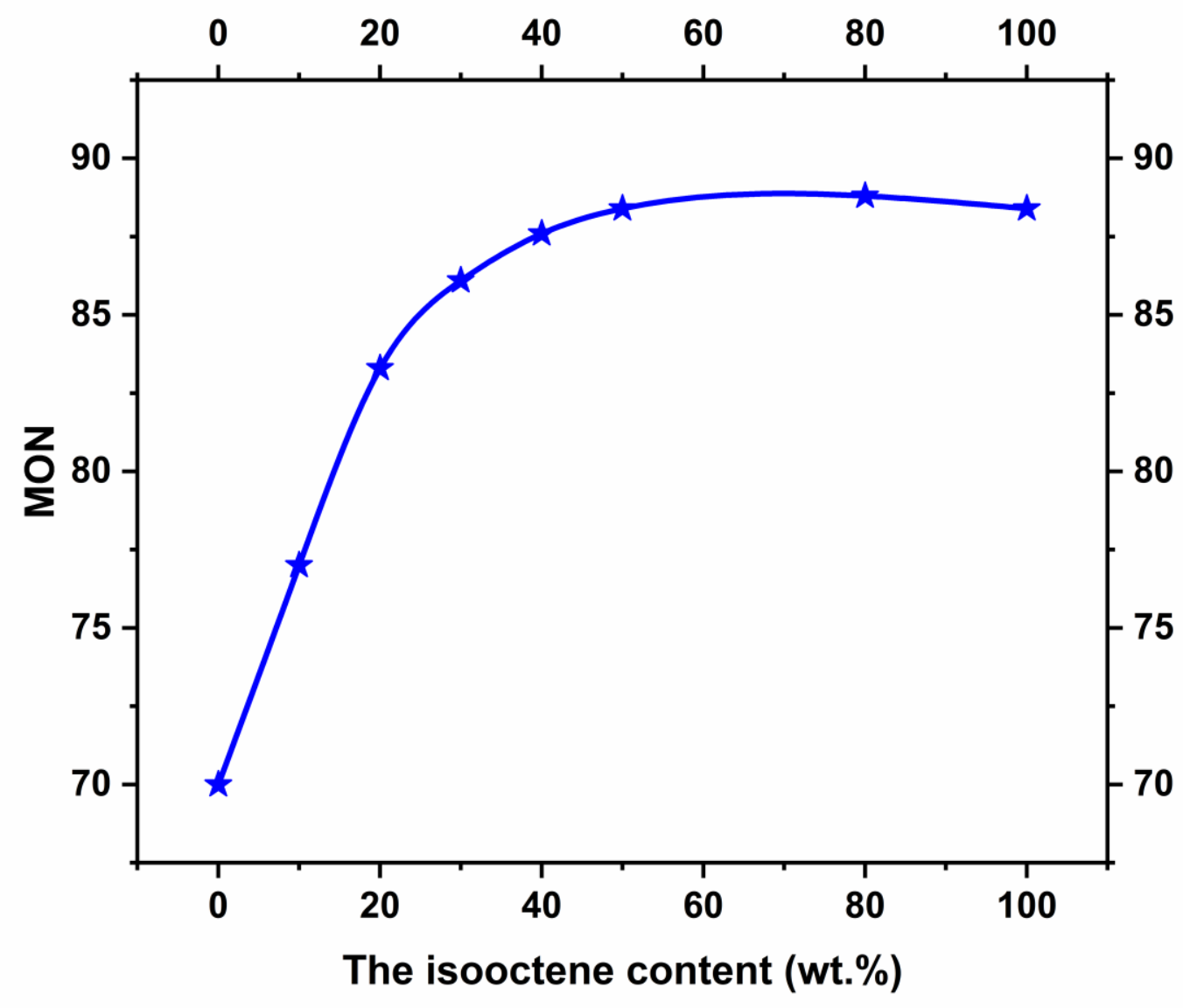

Fig. S4. Effect of isooctene on the change in the MON of the blend "70". 

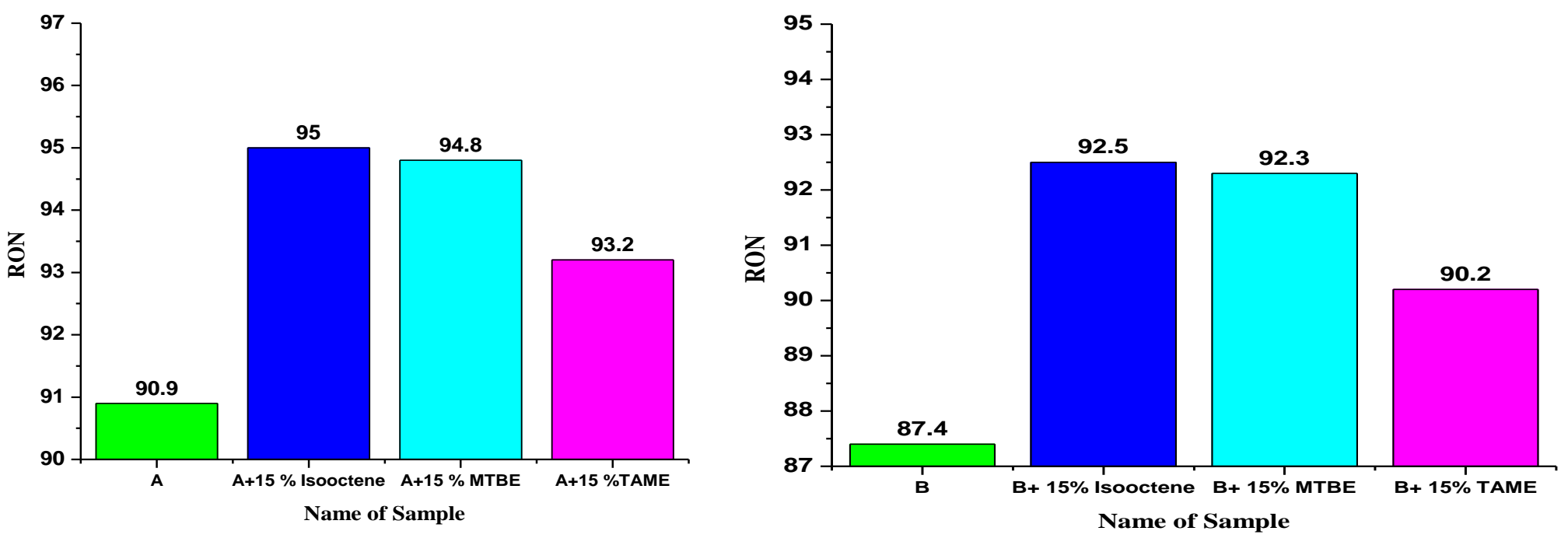

Fig. S5. Effect of isooctene on the change in RON of base gasoline A and B in comparison with MTBE and TAME. 

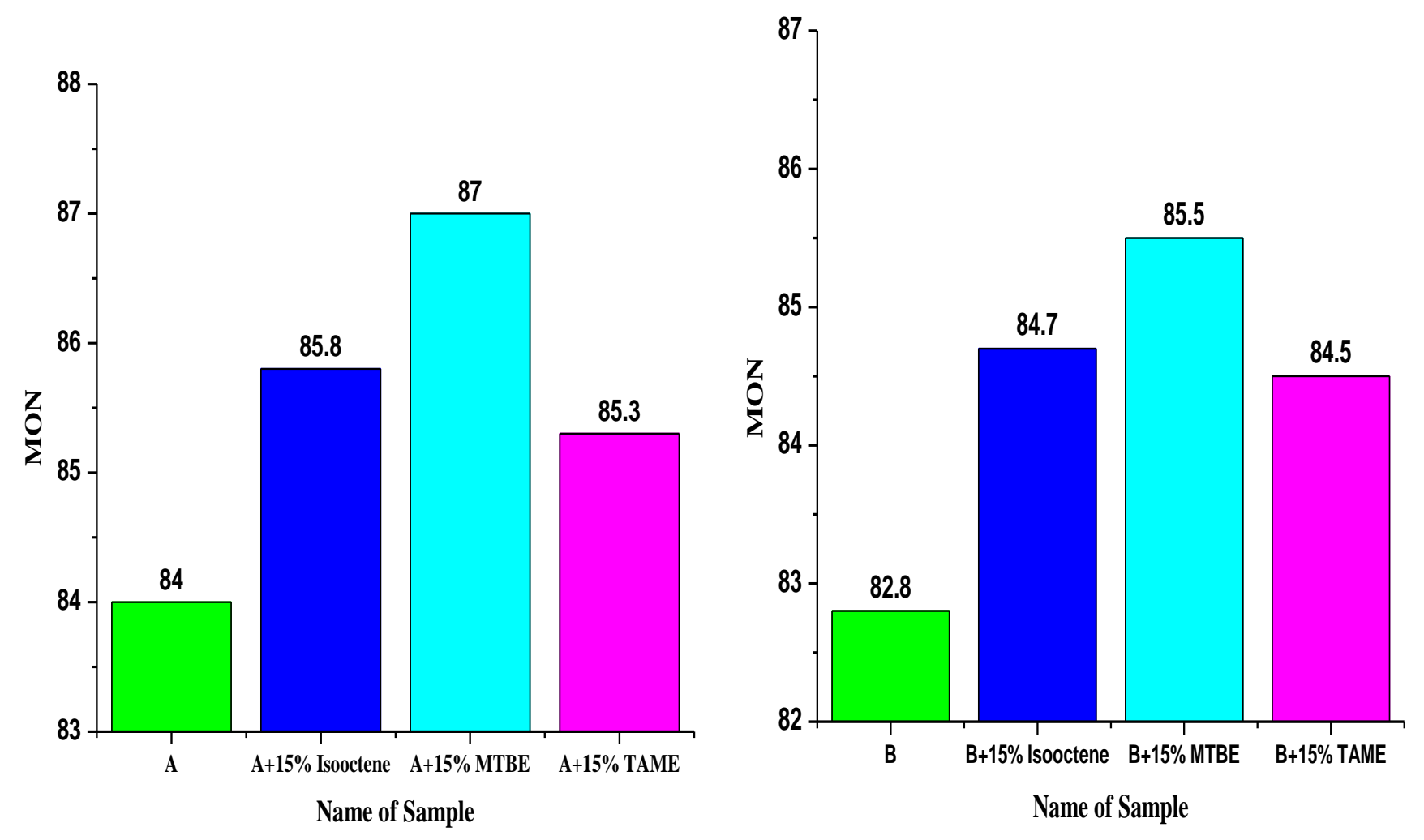

Fig. S6. Influence of isooctene on the change of motor octane number of base automobile gasoline (A and B), MTBE, and TAME 
Table S1. Physico-chemical and operational characteristics of the isooctene sample.

\begin{tabular}{|c|c|c|c|c|}
\hline No & Name of parameters & $\begin{array}{l}\text { Test } \\
\text { results }\end{array}$ & $\begin{array}{l}\text { Standard } \\
\text { methods }\end{array}$ & Test Method \\
\hline \multirow[t]{3}{*}{1} & Octane Number: & & & \\
\hline & RON & $112.9 *$ & Min. 95.0/98.0 & ASTM D2699 \\
\hline & MON & 88.4 & Min. 85.0/88.0 & ASTM D2700 \\
\hline 2 & $\begin{array}{l}\text { Density at a temperature of } 20^{\circ} \mathrm{C}, \mathrm{kg} \\
/ \mathrm{m}^{3}\end{array}$ & 723 & $720-775$ & ASTM D1298 \\
\hline 3 & Concentration of sulfur, $\mathrm{mg} / \mathrm{kg}$ & 8 & Max. 10 & ASTM D2622 \\
\hline 4 & Induction period, min. & 120 & Min. 360 & ASTM D525 \\
\hline 5 & $\begin{array}{l}\text { The concentration of washed gums, } \\
\mathrm{mg} / 100 \mathrm{~cm}^{3} \text { of gasoline }\end{array}$ & absence & Max. 5 & ASTM D381 \\
\hline 6 & Appearance & $\begin{array}{l}\text { Transpare } \\
\text { nt and } \\
\text { clean }\end{array}$ & $\begin{array}{l}\text { Transparent } \\
\text { and clean }\end{array}$ & $\begin{array}{l}\text { Transparent } \\
\text { and clean }\end{array}$ \\
\hline \multirow[t]{3}{*}{7} & $\begin{array}{l}\text { Volumetric fraction of hydrocarbons, } \\
\text { vol. } \%\end{array}$ & & & ASTM D6729 \\
\hline & - olefins & 89.9 & Max. 18 & \\
\hline & - aromatics & $<0.17$ & Max.35 & \\
\hline 8 & Benzene Content, wt.\% & $<0.17$ & Max. 1.0 & ASTM D3606 \\
\hline 9 & Oxygen Content, wt.\% & 0.28 & Max. 2.7 & ASTM D4815 \\
\hline 10 & $\mathrm{RVP}, \mathrm{kPa}$ & 12.4 & $45-100$ & ASTM D5191 \\
\hline 11 & $\begin{array}{l}\text { Corrosion of a copper plate ( } 3 \text { hours } \\
\text { at } 50^{\circ} \mathrm{C} \text { ), units on a scale }\end{array}$ & - & Class 1 & $\begin{array}{l}\text { ASTM D665/ } \\
\text { ASTM D7577 }\end{array}$ \\
\hline \multirow[t]{6}{*}{12} & $\begin{array}{l}\text { Fractional composition: volumetric } \\
\text { fraction of evaporated gasoline, } \% \text {, } \\
\text { at temperature: }\end{array}$ & & & \multirow{6}{*}{ ASTM D86 } \\
\hline & $70^{\circ} \mathrm{C}$ & 0 & $20-50$ & \\
\hline & $100^{\circ} \mathrm{C}$ & 20 & $46-71$ & \\
\hline & $150^{\circ} \mathrm{C}$ & 100 & Min. 75 & \\
\hline & $\mathrm{FBP},{ }^{\circ} \mathrm{C}$ & 118 & Max. 210 & \\
\hline & Residue in a flask, $\%$ (by volume) & 1.4 & Max. 2 & \\
\hline
\end{tabular}

* The definition of RON was calculated by using the calculation of the reference blend "70" (70\% by volume of isooctane and $30 \%$ by volume of $n$-heptane) containing $80 \%$ of isooctene. 
Table S2. Effect of isooctene on the change in octane numbers of base components and reference blend "70".

\begin{tabular}{lcccccc}
\hline Name of Component & \multicolumn{3}{c}{ Research method } & \multicolumn{3}{c}{ Motor method } \\
\cline { 2 - 7 } & $\begin{array}{c}\text { without } \\
\text { additives }\end{array}$ & $\begin{array}{c}20 \text { wt. \% } \\
\text { isooctene }\end{array}$ & $\begin{array}{c}\text { RON blend } \\
\text { isooctene }\end{array}$ & $\begin{array}{c}\text { without } \\
\text { additives }\end{array}$ & $\begin{array}{c}20 \text { wt. \% } \\
\text { isooctene }\end{array}$ & $\begin{array}{c}\text { MON } \\
\text { isooctend }\end{array}$ \\
Reference Blend"70" & 70.0 & 86.0 & 150 & 70.0 & 83.3 & 136 \\
Isomerate & 86.1 & 94.2 & 127 & 85.7 & 88.8 & 101 \\
FCC gasoline & 84.4 & 92.2 & 123 & 80.0 & 82.8 & 94 \\
Reformate & 96.7 & 98.9 & 108 & 87.0 & 88.1 & 92 \\
\hline
\end{tabular}

